Paper draft - for DesignIX conference in Berlin, 15-17 februari.

Version 10 November 2008

\title{
A chair to look to the moon What we can learn from irrational design history for contemporary design practice.
}

\section{Introduction}

The focus of product design is shifting from primarily offering functionality, towards experience and emotion driven product characteristics (Green, 2002). According to the theory of product phases (Eger, 2007), products will end in a phase characterized by individualization or awareness. Where the affective, emotional and abstract product values, become more and more important (Desmet, 2002; Norman, 2004). Individualization and awareness are, not accidently, also high up in Maslow's hierarchy of needs.

Different authors have different ideas about how to implement this emotion and affection in product design. Some of them even argue that affectivity is not influenced by the design at all, but only through the meaning that the user attaches to the product (Csikszentmihalyi, 1991/2007).

That this idea is not new, or even from the last decades, is illustrated by a Chinese chair design dating from the Ming-period (illustration 1). This chair type is referred to as a 'chair to look to the moon' instead of as a 'reclining chair'. In this way the chair is defined by the thing that you have to do with it, rather than by its functioning. And with this title the design opens up a whole of poetic associations like quiet nights on a veranda, clear skies, twinkling stars or even howling werewolves. By dreaming away with these associations you might even forget that the chair is actually not very comfortable. But this is an omission that is seen very often with Chinese furniture.

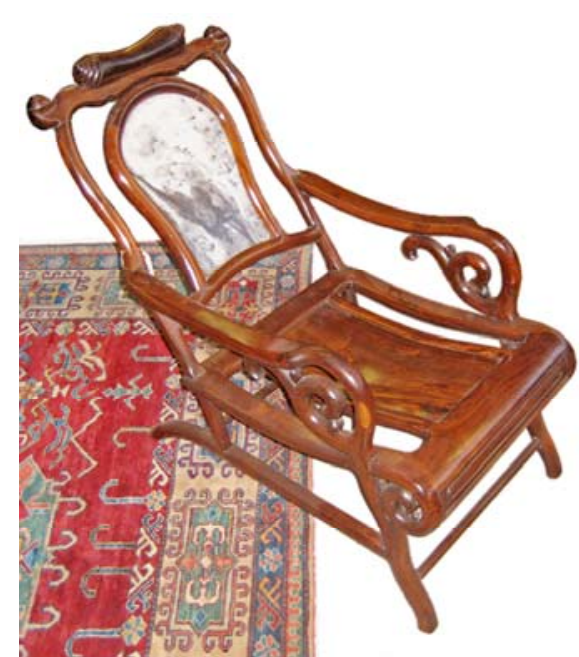

period design (I368 to I644) - Early 20th Century Republic hard wood replica

Research approach 
Whenever emotion is involved in the evaluation of a design, it seems that the mantra of the universal design-language, whereas according to the modernist movement, the shape of a product is directly derived from the (technical) functionality, is not very useful. And with respect to the ongoing miniaturization and multi-functionality of modern electronics, this phenomenon is not maintainable anyway (Bürdek, 1996). Consequently the contemporary designer has to look for other ways to fill his repertoire. A non-rational approach to product design might play an important role here, and for that reason it is interesting to analyze how designers have used this approach throughout the history of industrial products. In this way, principles, methods or approaches for contemporary design problems are derived from an historic analysis.

\section{Period}

This paper emphasizes on the period from circa 1990 to 2000, because then, the emotional orientation of the 'irrational' post-modernist designs of the 1980s (Horn, 1986; Sato, 1988; Vincenzo, 1989; Bellati, 1993) increasingly becomes connected with the function of products. And in this way interesting combinations of recognizable meanings and, for instance, new materials arise. A lot of products in this period do not stand out with their functional usability, but with the clearness of the idea behind it. The Netherlands are playing an important role in this development with the Droog label (Teunissen and Zijl, 2000).

This study tries to identify how interesting approaches and principles of this merely author-driven design practice can enrich the demand-driven design projects of industrial design engineers in our highly emotion-oriented environment nowadays.

\section{Ideas design}

In the early 90s the Droog label was established by Gijs Bakker and Renny Ramakers as a foundation for encouraging young talented Dutch designers. The first show with products of the label was at the Salone del Mobile in 1993 (Thomas, 2008). Among the designers contributing to the label in de early days were Peter van der Jagt, Tejo Remy, Arnout Visser and Gijs Bakker himself. With this label Ramakers placed herself in the middle of a stream of new designers she already foresaw in the late 80s. In 1987 she wrote "The 1980's have now produced a new generation of designers. Influenced by developments in architecture and by the Italian design groups Memphis and Alchimia, they are positioning themselves as artists more than ever before. Expressive qualities are for them the essence of design as well. But they are not production-oriented. The end product is simply the implementation of an idea." (Staal et al., 1987) [p224].

The label became world famous within a few years with design contributions from, amongst others, Marcel Wanders and Jurgen Bey. And at the beginning of this century the label was indicative for the broader stream of 'Dutch Design'. Looked upon from a designers perspective the products from the early period are merely simple, humoristic and explaining themselves. The 'Chest of Drawers' by Tejo Remy (illustration 2) consists exactly of a bunch of drawers. 


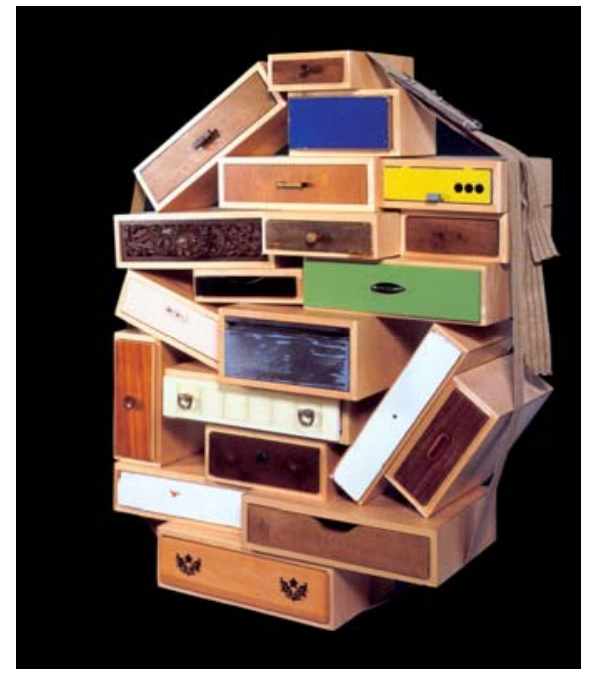

illustration 2, Tejo Remy - Chest of Drawers - 1991

The design is not particularly appealing, one can argue if it is really functional and it is certainly not a very efficient cupboard. But it is instantly recognizable and makes a lasting impression. It is also very personal because no bunch of pre-used drawers is the same and the owner of the chest can decide himself how the drawers are arranged. Remy even made an item where the drawers are grouped around a brand new television (Teunissen and Zijl, 2000).

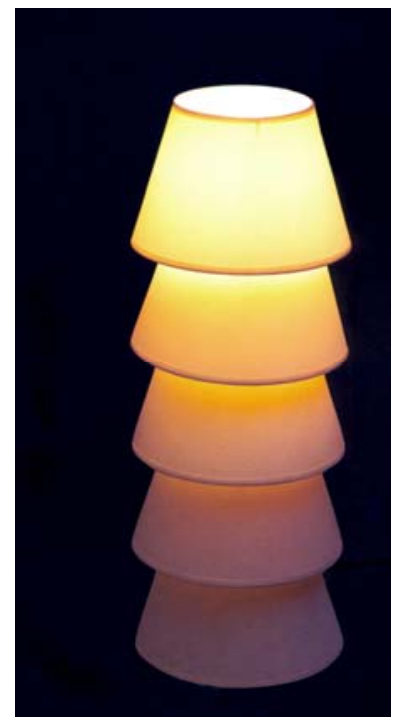

illustration 3, Marcel Wanders - Set Up Shades Lamp - 1989

The same instant recognition is derived with the 'Set Up Shades' lamp from Marcel Wanders (illustration 3), made out of standard lamp shades. The typical lampshade basic forms are like an archetype and at the same time the repetition of form gives it an interesting architecture. Like the similar 'Hollywood' lamps from Matteo Thun of the same year (illustration 4). 


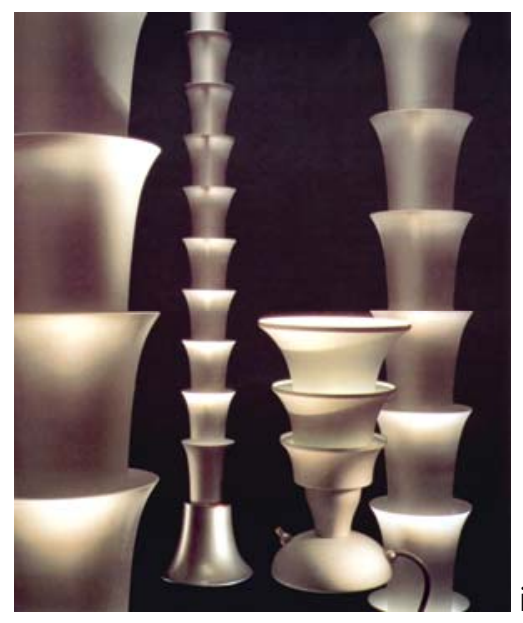

illustration 4, Matteo Thun - Hollywood Lamps - 1989

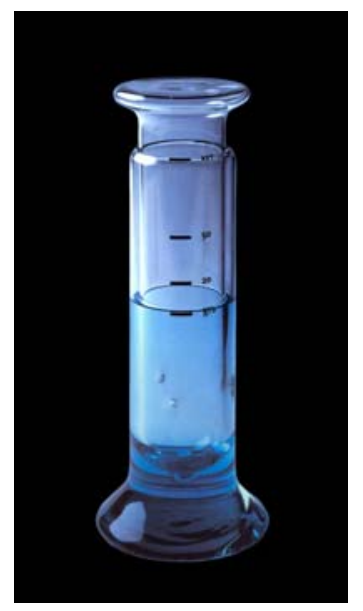

illustration 5, Arnout Visser - Archimedes Letter Scales - 1991

The nice thing about the letter scales from Arnout Visser (illustration 5) is that the functioning of the product is based on the principle of water-displacement and that this is recognizable for every user. The same self-explanation is found with the 'Bottoms-up' doorbell from Peter van der Jagt (illustration 6).

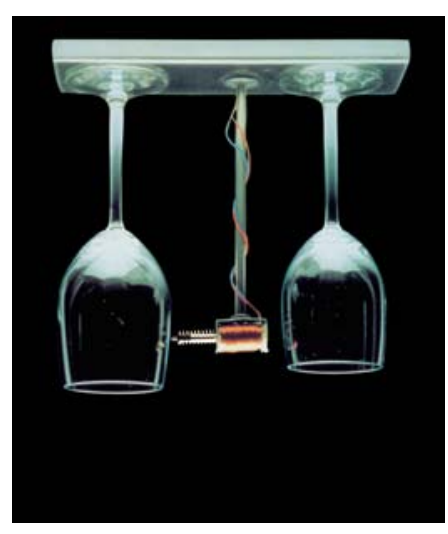

illustration 6, Peter van der Jagt - Bottoms-up Doorbell - 1993

Everybody knows that a crystal glass makes a nice sound when you hit it. By using this principle so explicit in a doorbell, the object becomes recognizable for every culture and background. And although its shape does not look like the restrained form giving propagated by the modernist movement at all, in this way the design actually does appeal to a universal language. It is not a design-language but more a 
product-language that is clearly understandable. Like with the chair to look to the moon, it is this clearness that makes you forgive the designer the fact that the product is in some ways not very practical. It is for instance very difficult to clean, especially when installed upside-down at the ceiling of the hallway.

The same forgiveness can be applied to the 'Knotted Chair' and 'Tree trunk Bench' from Marcel Wanders and Jurgen Bey. Two designs which are actually horrible to sit on, as you ever get the chance to try them.

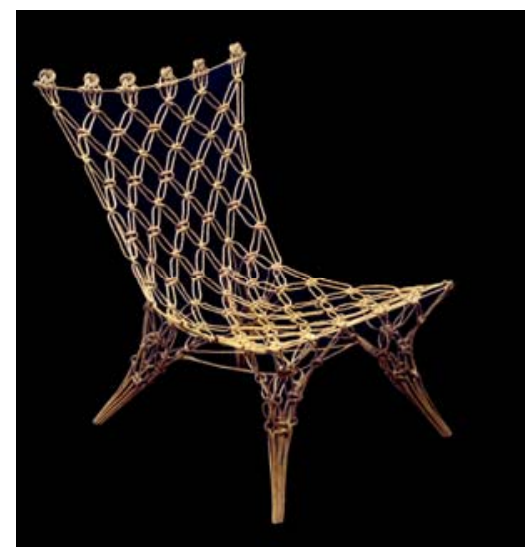

illustration 7, Marcel Wanders - Knotted Chair - 1995

From a designers perspective the Knotted Chair (illustration 7) is an interesting example of the combination of 'old' and 'new'. The way of making a shape by knotting a rope is very old and therefore recognizable, by combining this with a modern production technique (the rope is made from aramid fibre with a carbon core and cured with resin to behold its shape) the old fashioned craft becomes new.

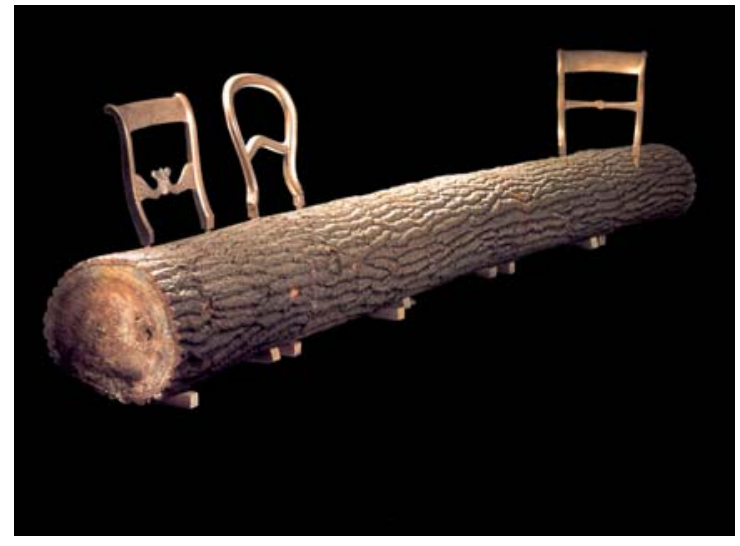

illustration 8, Jurgen Bey - Tree Trunk Bench

$-1999$

The Tree Trunk Bench (illustration 8) was designed for a park environment outside the seventeenth century mansion "Oranienbaum". Bey combined the natural appearance of the park in the form of a fallen tree with artificial backrests that were copied from the antique furniture from inside the mansion. With this approach we do not end up with a park-bench that is nice to sit on but the object is a wonderful combination of all the aspects of its surroundings. Not only the natural and the artificial but also the historic background and the idea of man- 
made nature is reflected in the sawn tree trunk and the bronze supports. And Teunissen and Zijl (2005) write "It is just as if the design, with its natural and fairytale appearance, had always existed" [p35]. Accidentally they are true in two ways, because the design very strongly resembles the 'Conoid" Bench by George Nakashima (illustration 9). This one-off piece of furniture was sold at a contemporary design auction at Sotheby's New York in 2006. Posthumously recognized as an important piece in American design history it was hammered off at 120.000 USD (Sotheby's, 2008).

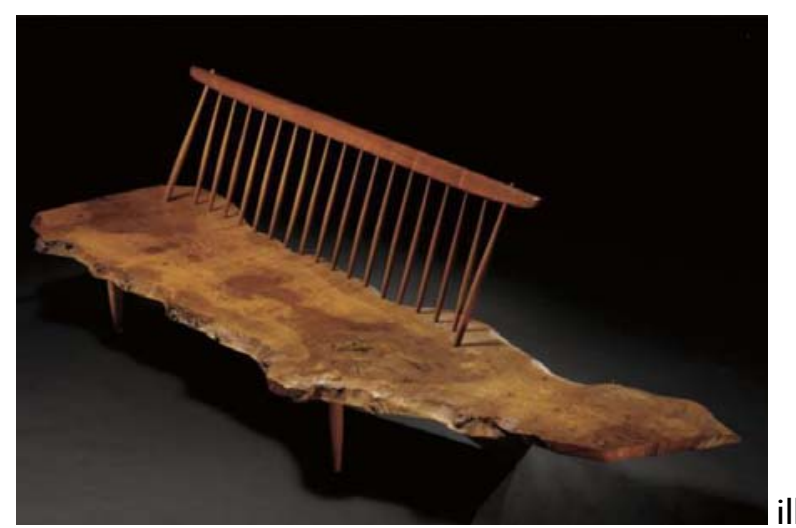

illustration 9, George Nakashima - Conoid"

Bench - 1960s

\section{Author driven- and Demand driven Design}

Several of the Droog designs are world famous and are present in a lot of museum collections. The Dutch became part of a new generation of personally successful designers following up the famous Italian post-modernists like Ettore Sottsass and Alessandro Mendini.

The success of the whole Dutch design movement was primarily based on this world-wide breakthrough of several Dutch designers like Marcel Wanders and Jurgen Bey mentioned before. But also people like Hella Jongerius and Richard Hutten. Their working practice is often referred to as Author-driven design, where the designer himself is the important driver in the creation, realization ánd evaluation of the design. There is some inverting effect in this personal success; first the designer becomes famous with a special design, later the designs become 'special' because of the fame of their designers. As a Dutch critic has said: "A design from Phillipe Starck that is not recognizable as such, has no purpose. It will not sell." (Weyel, 2007) [p.66]

The practice of Industrial Design Engineers can be described as Demand-driven design, where the design effort is applied to solve a need or a problem from a user or a client. These two approaches are different in their very nature. Because the industrial design practice is driven by the demand of the clients it is characterized by deadlines and budgets. To compel to these deadlines and budgets the work is structured by methods and processes. And to avoid risks, decisions are guided by marketing research, brand communication, briefings and lists of demands. For the author driven design practice one has to rely on the talent and fame of the designer. 
Even if the designer is making a design for a client, the personality of the designer comes first. Richard Hutten (2008) for instance explained at a meeting of the Royal Institute of Engineers in the Netherlands (KIVI-Niria, Ronde 60) that he is not looking for clients, but clients are contacting him when they want a design. When asked what the client actually demanded when he designed the 'Table Sofa' for Sawaya and Moroni he said literally; "They asked for a Richard Hutten" (illustration 10).

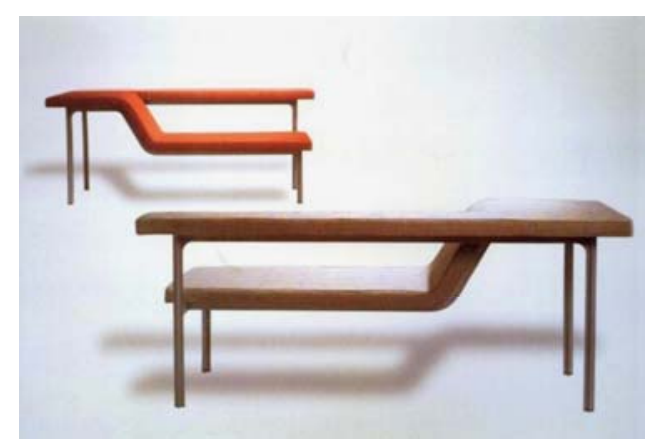

illustration 10, Richard Hutten - Table Sofa -

Sawaya and Moroni - 1999

A very useful characterization of both design practices was set up by Jeroen Verbrugge (2008) and communicated at a meeting of the same Royal Institute of Engineers in the Netherlands (table 1).

\begin{tabular}{|l|l|}
\hline Demand Driven & Author Driven \\
\hline Style of the client & Style of the maker \\
\hline Makes inherent & Makes special \\
\hline $\begin{array}{l}\text { Guided by marketing and } \\
\text { communication }\end{array}$ & Individual and intuitive decisions \\
\hline Structured by processes and methods & Dependent on creative finds \\
\hline 'Invisible' design & Fashionable and showy \\
\hline
\end{tabular}

Table I, characteristics of Demand driven and Author driven design (Verbrugge, 2008)

Another difference between the two categories is the cultural and economic impact. Philips (demand driven design) is making 12 million anonymous shavers a year at very low cost. Meanwhile the renowned 'Chest of Drawers' by Tejo Remy is considered a huge success at the Droog label by selling a just over hundred pieces at 16.600 Euro (Elzinga, 2007).

\section{Combining insights}

The best results however can be achieved when the best practices of both are combined. Marcel Wanders for instance was designing his knotted chair when experimenting at the Faculty of Aerospace Engineering at the Delft University of Technology at the invitation of the Droog Design label (Teunissen and Zijl, 2000). And Marcel Wanders is also cooperating with design agency Flex Development to 
incorporate more knowledge on industrial manufacturing and realization in his design projects (Verbrugge, 2008).

On the other hand the demand driven design practice can be incited to maximize creativity and freedom of expression within the margins of the briefing of the client. When the 'knotted chair' would have been designed from a list of demands, the first demand would be that the chair should be pleasant to sit on. The same applies to the 'Bottoms Up' doorbell. When it had to be easy to clean, we would never have had the inspirational aha-erlebnis (ding-dong) when looking at it now.

As a common denominator in all the previous designs we can see an approach where the 'idea behind the product' comes first, before the list of demands or any other controlling instrument. When the central idea of the product is clear, the shape and functionality of the product can be designed in a focussed way, with the result that the consumer will recognize the benefits easier. The iPod for example is one of the greatest successes in hand-held devices lately. But it is not very pleasant to hold in your hand and there are successors that have better functionality. But the central idea of 'simplicity' is very dominantly implemented (illustration 11 and 12).

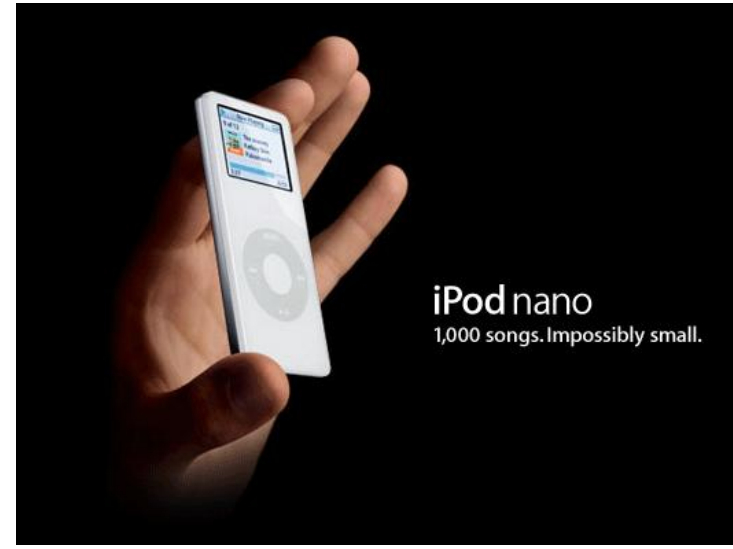

illustration II; iPod design communicates 'simplicity'

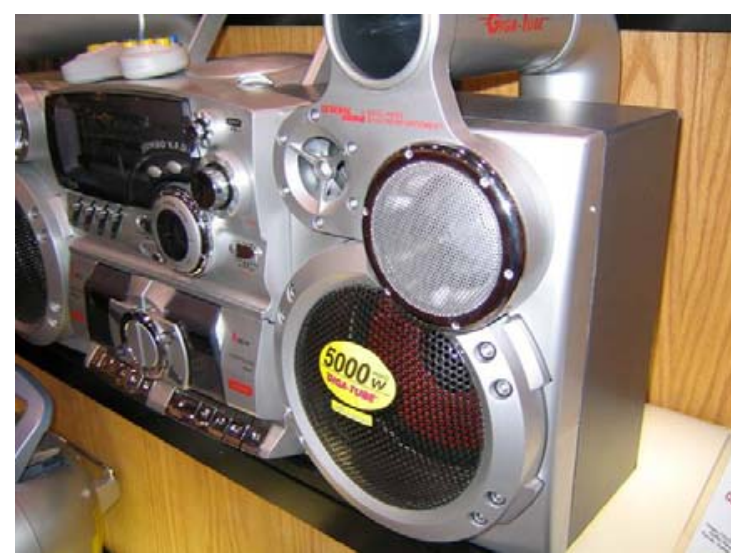

illustration 12; Sound system design does not communicate 'simplicity' 
Another fine example are the 'Foot Stickers' by Design academy graduate Frieke Seevers (illustration 13). In a project where Nike acted as a client she made soles that are glued to the foot when necessary. This lean design maximizes the idea of 'getting grip' that is so important for the sportswear manufacturer.

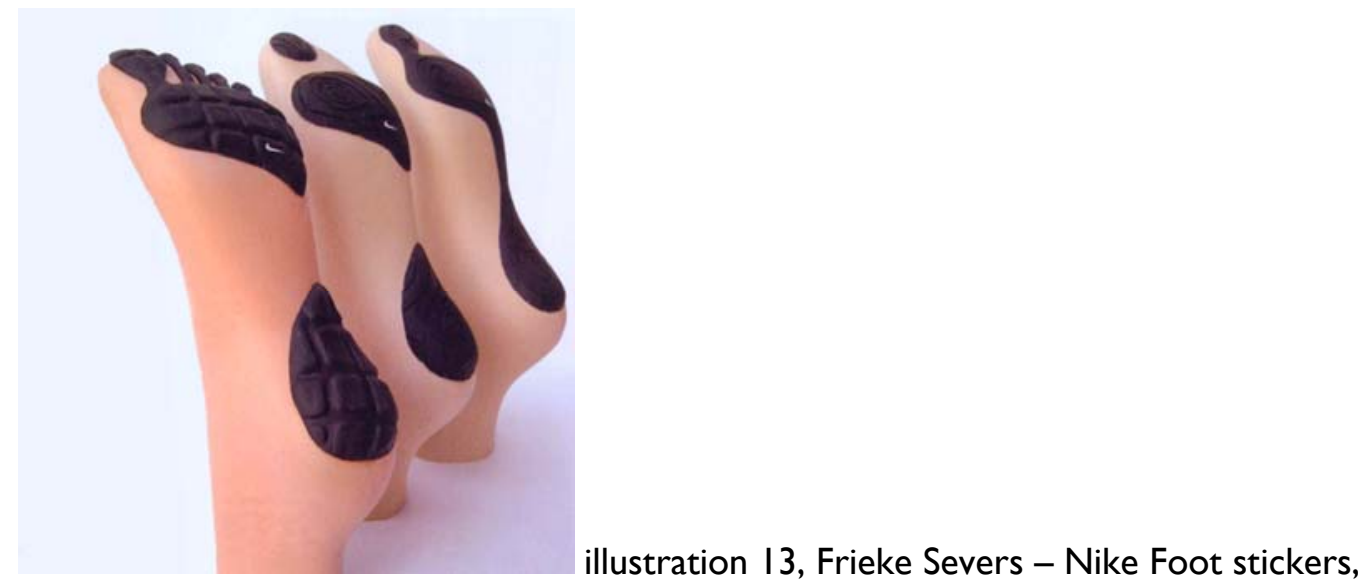

project at Design Academy Eindhoven in cooperation with Nike - 2005

An example from the design praxis of the design engineering education at the University of Twente is the augmented reality device designed by Tim Mengerink (illustration 14 and 15). In his master assignment for design agency Fabrique, in cooperation with the Royal Academy of Art (KABK in the Hague) he made an augmented reality application for museums.
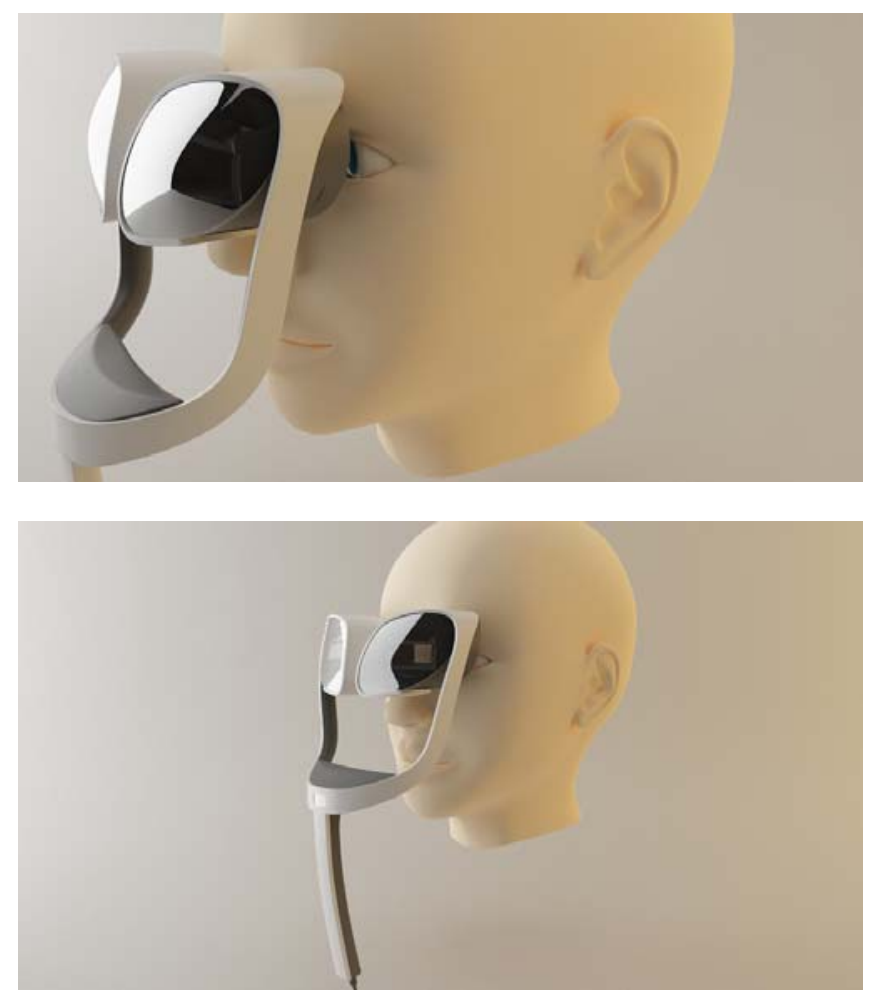
The visor which projects computer generated content onto the real museum environment was designed as a simple object. Just hold between you and the world, enhancing your vision like binoculars or glasses do. In the project the list of demands was grouped around the central design themes, visualizing the hierarchy between them (figure 1). There were three themes in this project, because besides the visor, also the computer application for the museum exhibition and the desk for distributing the visors had to be designed.

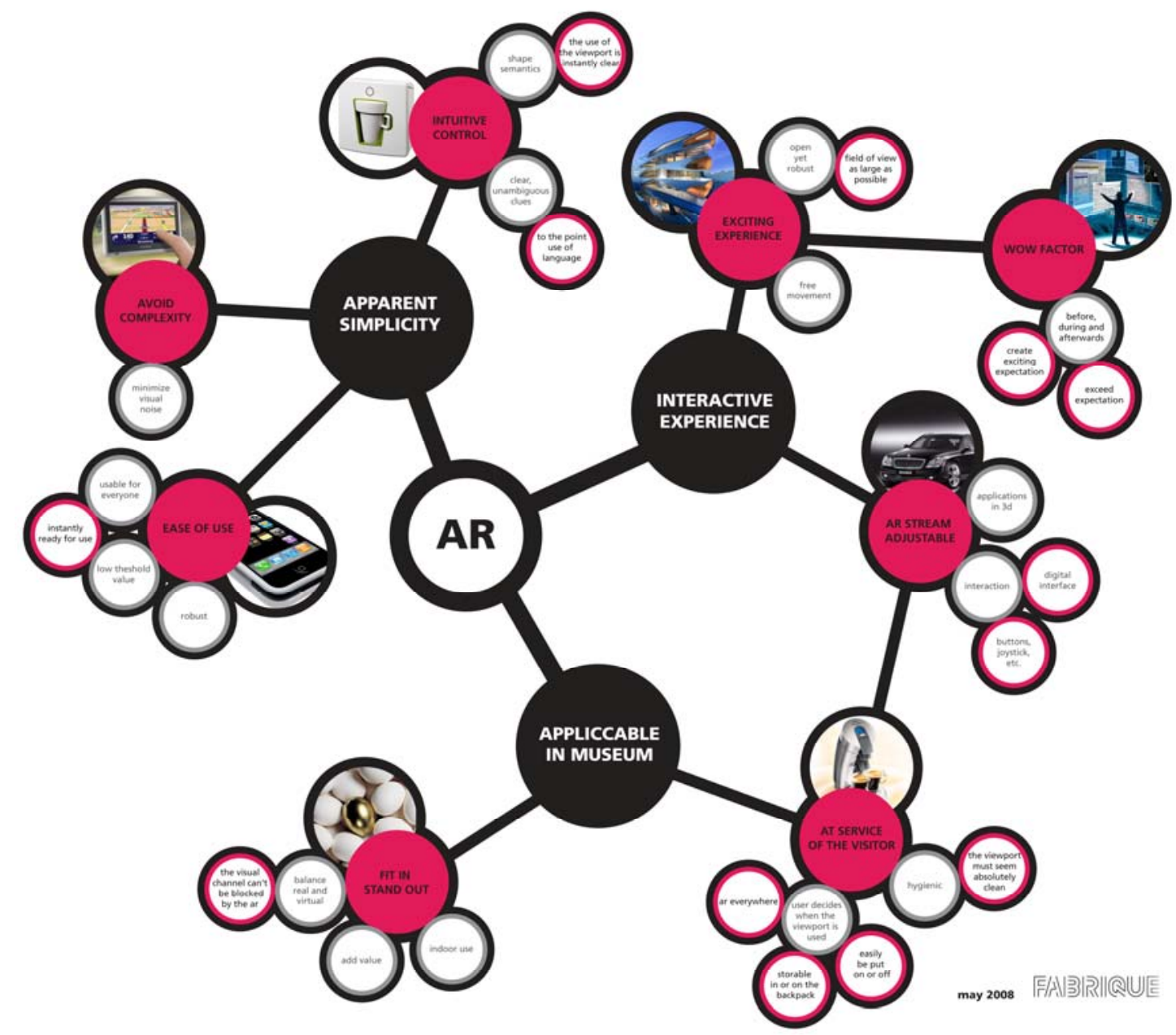

Figure I - Augmented reality design principles $(A R=$ augmented reality $)$ - Tim Mengerink 2008

\section{Conclusion}

So what should we do to get this poetic edge that was recognized in the 'Chair to look to the moon' into our product designs? We are encouraging our students to develop a sort of mission statement for their design projects. A central idea that will act as an umbrella for their design effort. Not holding in on methods or processes but adding a central theme to live to when developing alternatives or taking design decisions. Then the end result could have the same simplicity and self-explanation that characterizes the successful products of the Droog label. Methods and processes can still be maintained to master the complexity of the assignment. In this way even for demand driven design practice the conclusion can be; 'the end product is simply the implementation of an idea'. 
Assistant Professor, Laboratory of Design, Production and Management, University of Twente Enschede, OV, NETHERLANDS

Wouter Eggink (1972) graduated in industrial design engineering at Delft University of Technology in 1996 with a specialization in form-giving. From 2001 on, he has been teaching several design-courses with emphasis on design and meaning and design and society at the industrial design engineering education program of the University of Twente. Since 2007 he combines this work with a PhD. research on the history of Non-rational design.

\section{References}

Bellati, N. (1993). Italiaans New Design. Alphen aan den Rijn, Atrium/Terrail.

Bürdek, B. E. (1996). Design; geschiedenis, theorie en praktijk van de produktontwikkeling. 's Gravenhage, ten Hagen \& Stam.

Csikszentmihalyi, M. (1991/2007). "Vormgeving en orde in het dagelijks leven" Morf 7: 7-15.

Desmet, P. M. A. (2002). Designing Emotions. Industrial Design. Delft, Delft University of Technology. PhD: 272.

Eger, A. O. (2007). Evolutionaire productontwikkeling; productfasen beschrijven de meest waarschijnlijke levensloop van een product. Den Haag, Lemma.

Elzinga, G. (2007). "Droog Design; Initiatief \& Inspiratie" Audi Magazine 2007: 6669.

Green, B. (2002). Pleasure with Products: beyond usability - Introduction. Pleasure with Products; beyond usability. W. S. Green and P. W. Jordan. London, Taylor \& Francis: 1-5.

Horn, R. (1986). Memphis; objects, furniture \& patterns. New York, Simon \& Schuster.

Hutten, R. (2008). Richard Hutten. Lecture. Utrecht, KIVI-Niria - Ronde 60.

Norman, D. A. (2004). Emotional Design; Why we love (or hate) everyday things. New York, Basic Books.

Sato, K. (1988). Alchimia; Contemporary Italian Design. Berlin, TACO.

Sotheby's. (2008). "Important 20th Century Design - 14 June 2006 - New York." Retrieved 15-08, 2008, from http://www.sothebys.com/app/live/lot/LotDetail.jsp?sale_number=N08214\&li ve_lot_id=112.

Staal, G., H. Wolters, et al. (1987). Holland in Vorm; Dutch design 1945-1987. 's Gravenhage, Stichting Holland in Vorm.

Teunissen, J. and I. v. Zijl (2000). Droog \& Dutch Design. Utrecht, Centraal Museum.

Thomas, M. S. (2008). Goed in Vorm; Honderd jaar ontwerpen in Nederland. Rotterdam, 010.

Verbrugge, J. (2008). Vraag en Aanbod gestuurd Design; gelijk, complementair of ongelijk? Lecture. Utrecht, KIVI-Niria - Ronde 60.

Vincenzo, G. P. (1989). Memphis; 1981-1988. Groningen, Groninger Museum.

Weyel, I. (2007). "Weg met design!" Eigen Huis \& Interieur 2007: 65-66. 